\title{
SOME MEDICINAL PLANTS AMONG THE TRIBES OF CHHATARPUR DISTRICT (M.P.) INDIA
}

\author{
Amita Arjariya and Kalpana Chaurasia \\ Department of Botany \\ Government Autonomous Maharaja College \\ Chhatarpur (M.P.), India
}

\begin{abstract}
The Chhatarpur District in central India is home to numerous herb species. The agro-climatic conditions prevailing in the region provide an ideal habitat for the natural growth of a variety of plants and herbs, which provide raw materials for pharmaceutical, phytochemical, food, flavoring and cosmetic industries. The paper provides information on 58 medicinal plants used by the Gond, Bhil and Bediya tribes of Chhatarpur district of Madhya Pradesh, India, for the treatment of various diseases. Traditional medicine remains an integral part of the health system in this area. Medicinal plants of forest origin hold great promise to enhance the health and livelihoods of the forest dwellers.
\end{abstract}

Key words: Ethno medicinal, tribes, medicinal plants, traditional uses, diseases.

\section{INTRODUCTION}

Madhya Pradesh is veritable niche of growing healing herbs, which are being used in Indian system of medicine like Ayurveda, Siddha and Unani. The plants of immense medicinal value are abundantly found in Chhatarpur District. Madhya Pradesh has got 1,35,164 sq $\mathrm{km}$ of forest which accounts for $30.48 \%$ of total geographical area of the state. Medicinal and aromatic plants are important products found in forest areas throughout Madhya Pradesh from the plains to the hills. More than 80 percent of the people in Madhya Pradesh (India) rely on herbal remedies as a principal means of preventing and curing illnesses and following traditional system of medicine. There are several advantages to such systems: the plants involved are readily available, easy to transport, and do not spoil quickly.
Remedies based on these plants often have minimal side effects, and the relatively high cost of synthetic medicines often makes traditional herbal medicines an affordable choice for the poor in these lands. India's traditional medical systems are part of a time-honored and time-tested culture that still intrigues people today. A culture that has successfully used nature to treat primary and complex ailments for over 3,000 years obviously has a contemporary relevance.

This work concentrates on potential ethnomedicinal value of plants commonly used by the tribals residing in and around Chhatarpur district of the area surveyed. The area of exploration lies in the Central part of Madhya pradesh at Chhatarpur district at $23^{\circ} 10^{\prime}$ to $25^{\circ} 20^{\prime}$ North latitude and $78^{\circ} 59^{\prime}$ to $80^{\circ} 26^{\prime}$ 'East longitude. District Chhatarpur is a part of Central India and 
lies in Satpura hill ranges adjoining Vidhyanscarp and bounding Uttar Pradesh. Tribal communities like Bhil, Gond and Bediya inhabit it. All these tribal communities use plants for curing various disorders. Although ethnobotanically this region is under exploration, but still a vast area remains untouched due to the displacement of the original population. A perusal of literature revealed that some work has been done on ethnomedicinal plants of Madhya Pradesh Pandey and Bisaria (1997), Rai and Pandey (1997), Pandey (2000), Rai et al. (2000) and Arjariya and Chaurasia (2008). The present study aims to identify and prepare an inventory of various medicinal plant species used by the tribals of Chhatarpur District of central India to cure their various ailments.

\section{MATERIALS AND METHODS}

Following the method of Jain and Goel (1995), the information regarding the usage of medicinal plants available in the local area for treating various ailments and diseases was collected directly by contacting the herbal doctors and the persons who have knowledge about these medicinal plants in the Chhatarpur district. The present study was carried out in Chhatarpur district during March 2006 to February 2008. The ethnobotanical data were collected through interviews, discussion and observations. Care was taken that elders were part of each group, as they had more knowledge about plant uses. Information was recorded specially from native people who were familiar with local herbal medicines.

\section{RESULTS}

The data on medicinal plants collected from inhabitants in and around Chhatarpur district were pooled and analysed. The investigation revealed the 58 medicinal plant species belonging to 54 genera and 35 families, commonly used for ailments by various tribes in the area surveyed. The enumeration and utilization of these plants are described below.

Abrus precatorius Linn. (Ghumachi) Fabaceae: Seeds are used as purgative and abortifacient.Root paste prepared from goat's milk is dropped into the eye till the cure. Seed powder is used externally in rheumatism. The dried root powder (5-10 g) mixed with honey is given in cough and cold for about a week.

Acacia catechu Willd. (Khair) Mimosaceae: The bark of the tree is used in chronic diarrhea. Bark powder mixed with water is used in conjunctivitis. Externally applied to eruption in boils.

Acacia nilotica (Linn.) Willd. Ex Del., Syn. A. arabica (Lamk.) Willd. (Babul) Mimosaceae: The twig of the plant is used as natural tooth brush. The extract of fresh bark is used as tonic, and gum is used as powerful tonic after delivery. The bark used as poultice in ulcer. The leaves are worm out and given orally in diarrhea.

Achyranthes aspera Linn., Syn. A. porphyristachya Wall. ex Moquin. (Latjira) Amaranthaceae: Twigs are used for tooth pain. Roots of the plant tied to women for easy delivery of baby. Leaves are used in scorpion sting and in skin eruptions. Leaves burned with camphor and used externally in cataract (eye diseases). Paste of root is applied externally in snake bite.

Adhatoda vasica Nees., Syn. Justicia adhatoda L. (Adusa) Acanthaceae: The decoctions of leaves are given to cure asthma and other bronchial troubles. Juice of leaves is given along with goat's milk in tuberculosis up to 6 months.

Aegle marmelos (L.) Corr. (Bel) Rutaceae: Fruits are used in dysentery and diarrhea. Bark decoction used orally in intermittent fever. Root, barks and pulp of fruit with sugar used in bronchitis. Bark decoction with oil of Ricinus communis is used in skin diseases. 
Aloe vera ex. Linn. (Gwarpatha) Liliaceae: The peelings of the leaves are used in skin burn. The gel of the plant is given orally in ulcer. The fleshy part is also used as facial cream. Gum and resin are astringent and purgative and also used in constipation and menstrual suppression.

Annona squamosa Linn. (Sitaphal) Annonaceae: The leaves are used to reduce blood sugar. The oil of seed is used to kill lice. The root is given in acute dysentery and spinal diseases. The bark is given in diarrhea and also used as a tonic. Bark juice is given as an antidote for snakebite.

Anogeissus latifolia (Roxb. ex DC.) Wall. ex Guill. and Perr. (Dhawra) Combretaceae: Leaves are used in diarrhea. Gum is used as tonic. Paste of the bark when mixed with pepper is used in dry cough. Dried stem bark powder, mixed in hot water and made into a paste is applied on head to relieve headache.

Argemone mexicana Linn. (Pili Katari) Papaveraceae: The extract is used in various skin diseases. The latex is applied in eyes in case of conjunctivitis. Smoke of the seeds is used to relieve toothache. Yellow juice of this plant mixed with powder of Jamun and mustard oil, made in to a paste and applied externally for ringworm and eczema.

Asparagus racemosus Willd. (Satavar) Liliaceae: The root powder is used to increase vigour and strength. The root powder is also used to increase lactation. Juice of fresh roots given orally in dysentery. Fresh root juice is mixed with honey and given for dyspepsia. Root paste used externally against venereal diseases.

Azadirachta indica A. Juss (Neem) Meliaceae: Seed oil is used in skin diseases and in lice. Bark is useful in malarial fever. Tender twigs are used as tooth brush. Powder of bark used externally against venereal diseases. The fruits are recommended for urinary, piles and intestinal warms, crushed leaves applied on eczema of feet and head for inflammation.

Bauhinia variegata Linn. (Kachnar) Caesalpiniaceae: Bark is used in skin diseases. Dried buds are given orally in dysentery, diarrhea and worms. Powder of young pods (1 tsp. every 4 h) is given to cure stomachache, eye problems and headache.

Boerhaavia diffusa Linn. Syn. (Punarnava) Nyctaginaceae: Plant used in jaundice, urinary troubles and in skin diseases. Decoction of plant with leaves of Tulsi, used orally in dry cough. Juice of fresh root given orally in stomachache. Dried plant powder smoke to get relief from asthma.

Boswellia serrata Roxb. ex. Colebr., Syn. B. glabra. Roxb. (Salai) Burseraceae: Gum used as tonic. It is considered as diuretic and useful in skin diseases. Root paste is applied externally in small pox and chicken pox. Powder of shade-dried leaves mixed with coconut oil is said to be useful in curing the burning and scaled skin.

Bryonopsis laciniosa acute. Non (L.) (Shivlingi): Cucurbitaceae. Seeds are used to cure sterility in women. Fruits are burnt and given orally in dry cough.

Butea monosperma (Lamk.) Tolbert., Syn. B. frondosa Koenm. ex Roxb. (Palas) Fabaceae: Seeds are used to cure ringworms and skin diseases. Seeds, pounded with lemon juice, when applied to skin act as rubefacient. Red gum is used in the treatment of diarrhea and dysentery. Powder of leaves with honey given orally in impotency. Seed powder is applied in scorpion sting.

Caesalpinia bonduc (Linn.) Roxb., Syn. $C$. bonducella (Linn.) (Gataran) Caesalpiniaceae: Seed oil is useful as cream for brightness of face. Kernels pounded, mixed with oil, and applied to relieve body ache. Seed powder is given to ladies against bleeding. 
Calotropis procera (Ait.) R. Br., Syn. Asclepias procera (Ait.) (Aak) Asclepiadaceae: The latex of plant is applied to remove thorn from the body and also in boils. Latex of leaves is used to give relief from scorpion sting and as a blistering agent. Dried leaves are grind and mixed with cow's milk and taken orally for the treatment of gonorrhea and syphilis. Paste of the roots when mixed with boiled water or milk 1:2 ratio and given twice a day, it is believed that it cures asthma and cough.

Cassia tora Linn. (Chakoda) Caesalpiniaceae: The seed paste is applied on skin diseases. The powder of dry seeds is used to cure asthma. Seeds are collected, roasted and then crushed with coconut oil to apply on itching and eczema, scabies. Leaves and seed decoction used externally in blood spot eye.

Celastrus paniculatus Willd., Syn. C. nutans Roxb. (Malkangni) Celastraceae: Massage with the seed oil is done on joints to relieve pain. Root paste with jaggery is given for epilepsy. One or two drops of oil of seed with sugar is given thrice daily before meals in stomach ulcer. Root and leaves are pounded as a poultice to relieve headache.

Centella asiatica Linn., Syn. Hydrocotyle asiatica Linn. (Bramhi) Apiaceae: The leaves are used to improve memory. The plant is mashed into a paste and applied on boils and tumors. Syrup made from leaves when mixed with small ginger and black pepper is taken as a cough syrup. It is given thrice a day for one week. A decoction of the whole plant is used in treatment of leprosy, it is given thrice a day for 21 days.

Cissampelos pariera L., Syn. C. hirsuta Buch. Ham. ex DC. (Karu Pahad) Menispermaceae: The root of the plant is used in snakebite. The root decoction is also used in diarrhea and urinary troubles.
Curculigo orchioides Gaertn. (Kali Musli) Hypoxidaceae: Roots are used as tonic and aphrodisiac in leucorrhoea and menstrual irregularities. The tubers are pounded with ajwain and a decoction is obtained, given to children suffering from disease of becoming unconscious. The powdered rhizome put into cuts to stop bleeding and to dry up the wounds.

Cuscuta reflexa Roxb. (Amarbel) Convolvulaceae: The extract of the plant is used in white spots and in dandruff. The whole plant and black pepper (2:1) are crushed and the aqueous extract is taken orally twice a day for spermatorrhoea. Twig of stem added with Tulsi and gur given orally in cough. Plant extract is used in leucorrhoea and as blood purifier.

Dalbergia latifolia Roxb. (Kala Shisham) Papilionaceae: Fumes of Shisham wood and pods of Cassia fistula are applied to head of cattle to cure fever of cattle. Wood extract is applied in skin diseases and pimples. The stem bark along with the bark of $D$. paniculata is pounded in water, is given to relieve body pain.

\section{Dalbergia paniculata Roxb. (Mohli)} Papilionaceae: Bark is useful in body pain. Juice of leaves is used in skin diseases.

Dalbergia sissoo Roxb. (Shisham) Papilionaceae: Powder leaves are mixed with black pepper mishri and cow milk given regularly in spermatorrhoea. Pounded leaves are applied on eyes in conjunctivitis.

Datura metal Linn. (Dhatura) Solanaceae: Smoke of seeds inhaled in bronchial troubles. Leaves soaked in hot oil are tied over sprained parts. Leaves are made into Bidi and are smoked in asthma and bronchitis. Seed extract is applied on dog bite. Roots are boiled in milk and administered with "ghee" in asthma and cough. 
Delonix regia (Bajer) Raf. (Jamun) Caesalpiniaceae: Seeds are useful in pyorrhea. A few leaves are roasted, crushed and wrapped in a piece of cloth and inhaled just after scorpion bite. The leaves are used as a purgative and also in rheumatism. The infusion of flowers is prescribed in bronchitis, asthma and malarial fevers.

Diospyros melanoxylon Roxb,. Syn. D. exculpta Buch-Ham. (Tendu) Ebenaceae: Bark of the tree is used in diarrhea. Dried flowers are useful in skin and urinary diseases. Paste of the root is applied externally in scorpion sting. The fruits are used orally also in scorpion sting. Bark decoction used as an eye lotion. Leaves are used for wrapping bidis used to stop the formation of gas in stomach.

Eclipta alba (Linn.) Hassk., Syn. Eclipta prostrata (Linn. F.) Linn. (Kala ghamra) Asteraceae: Applied with oil to reduce graying of hairs and hair loss. Juice of the leaves applied through ear against pain of jaw. Plant extract is given for diarrhea and disorders of liver and spleen. The decoction of leaves is mixed with sugar is given 3 times a day to cure fever and malaria.

Emblica officinalis Gaertn., Syn. E. phyllanthus Linn. (Amla) Euphorbiaceae: Fruits are used in digestion and as tonic. It is considered to be a good blood purifier. Juice of leaves is given to cure scorpion stings. Poultice of fruits is useful to stop bleeding from cuts. Seed are used in the loosening of bowels and also useful in eye and hair wash.

\section{Evolvulus alsinoides (L.) (Sankhpuspi)} Convolvulaceae: The plant is used to improve memory and in mental diseases.

Gymnema sylvestre (Retz.) R. Br. ex Roem. and Schult. (Gurmar) Asclepiadaceae: The leaves of the plant are used in diabetics. Fresh leaves chewed to keep urine clear. The root is held in repute as a remedy for snake bite.
Helicteres isora Linn. (Marodphalli) Sterculiaceae: Powder of ripe fruits and stem bark is employed in dysentery and diarrhea. Leaf juice is beneficial in stomach affections, also used in diabetes. About 4 teaspoon of root juice mixed in hot water is given twice a day for about a week to treat rabies. The aqueous extract of seed in smaller dose is given twice a day for 7 days to children in stomach pain.

Hollarrhena antidysentrica (L.) Wall ex DC. Syn. H. pubescens (Buch.-Ham.) Wall. ex. Don. (Kutaj) Apocynaceae: The milky latex is applied externally on wounds. Dry stem bark grind, powder mixed with coconut oil and applied on white spot. The bark pounded in water kept for 2-3 hours, and given a liquid, employed for treating stomach disorders.

Leucas aspera Link., Syn. L. plukenetii (Roth.) Spreng. (Gopha) Lamiaceae: One table spoon full aqueous extract of seeds once a day given for three days after menstruation to check conception. The decoction of crushed leaves is given through nostrils to cure snake bite. The juice of roots is put in nostril in half headache. Leaf juice is put into eyes 2 or 3 times daily in burning sensation and redness of eye.

Mallotus philippensis (Lamk.) Muell.-Arg., Syn. Croton philippensis (Lamk.) (Roli) Euphorbiaceae: The powder from the exterior of the fruits is used for roundworms. Fruit paste or oil obtained by boiling the fruit powder in coconut oil is applied on the eruption.

Mitragyna parviflora (Roxb.) Korth., Syn. Stephegyne parvifolia Korth. (Mundi) Rubiaceae: Bark of the tree is used in fever and cold. Paste of stem bark is applied in muscular pains. Root grind with water and extract given orally in the treatment of snake bite. 
Moringa oleifera Lamk., Syn. M. pterygosperma Gaertn. (Sanjana) Moringaceae: The paste of the leaves is applied externally on wounds. The crushed bark is boiled in mustard oil for use as a balm in case of acute traumatic pain. Leaves are given in itching and eczema. Flower used as a tonic and to promote the urin discharge.

Mucuna pruriens (Linn.) DC., Syn. M. prunta Hook. (Kewanch) Fabaceae: The seeds are used as aphrodisiac and in male sterility. The roots are useful in dysentery and in uterine trouble. Hair of pod scrapped off with a knife, mixed in gur (solidified sugarcane juice) and made in to pills to kill stomach worms in children and calves. Burnt seeds are eaten in cough and cold.

Nyctanthus arbor-tristis Linn. (Harsingar) Nyctanthaceae: The inflorescence and young fruits are pounded in water, and given in relieving cough. One teaspoonful leaf decoction is given with honey twice a day for three days in the intermittent fever. Paste of leaves applied on eczema, ringworm and boils. Bark is mixed with bark of Terminalia arjuna and mashed the resulting paste is rubbed in the case of internal injuries.

Ocimum basllicum Linn. (Maruadana) Lamiaceae: The leaf decoction mixed with saline water is used to keep away the snakes. Leaf juice is dropped in to ear, for earache. Leaves are rubbed externally on ringworm, scabies and other skin disease.

Ocimum sanctum L., Syn. O. tenuiflorum L. (Tulsi) Lamiaceae: The leaves are used to cure cough and cold and also to cure boils and ulcers. The seeds are used as aphrodisiac. The expressed juice of leaves gently warmed with equal amount of water is given to the children for pneumonia. Leaves are used in headache, are also rubbed in skin diseases.

Pongamia pinnata (Linn.) Piker., Syn. P. glabra Vent. (Karanj) Fabaceae: The seed oil is applied on skin eruptions and eczema. Seed paste applied on the boils. The poultice of leaves is applied to ulcers infected with worms.

Rauvolfia serpentina (Linn.) Benth. ex Kurz. (Sarpagandha) Apocynaceae: It is a reputed household medicine for the treatment of sanity insomnia and snakebite. A decoction of the root (3 g) and black pepper is given to expel intestinal worms in children. The root juice is taken raw or boiled to bring down the body temperature.

Sida cordifolia Linn. (Bala) Malvaceae: The plant is used as anti-rheumatic and antipyretic drug. The expressed juice of the roots is used for external injuries, cuts, etc. Root bark ground with milk and sugar is taken for leucorrhoea.

Solanum indicum Linn. (Kushmi) Solanaceae: The leaf paste is applied on the wound inflicted by a black snake.

Sterculia urens Roxb. (Kullu) Sterculiaceae: Root powder mixed with honey and given to pregnant lady for easy delivery. Leaf juice applied externally in venereal diseases. Bark and gum used for throat infection and tooth disorders. Gum soaked in water and mixed with sugar given for diarrhea, once a day for 2 days.

Syzygium cumini Linn. Skeels., Syn. Eugenia jambolana [Lamk.] DC. (Jamun) Myrtaceae: Seed-powder is useful in diarrhea, dysentery and diabetics. Decoction of bark is used as mouthwash in sore throat.

Tamarindus indica Linn. (Jamun) Caesalpiniaceae: A poultice of fresh leaves is useful in swellings, boils and for relieving pain. Seed paste applied on site of scorpion bite. Decoction is prepared from fresh bark, a dose of 5$10 \mathrm{ml}$ decoction is used in diarrhea. Leaf extract $(10 \mathrm{~g})$ with rhizome paste of Curcuma longa $5 \mathrm{~g}$ put on the forehead for reducing headache.

Terminalia arjuna [Roxb.ex DC.] Wt. and Arn., Syn. T. glabra Wight and Arn. (Arjun or Kahua) 
Combretaceae: The decoction of the bark is used in heart troubles. The bark gives strength to the heart. Fruit decoction of the plant is mixed with fruits decoction of amla and given orally in constipation. Paste of leaves applied on cuts to stop bleeding.

Terminalia bellirica (Gaertn.) Roxb., Syn. Myrobalanus bellirica Gaertn. (Baheda) Combretaceae: Epicarp of the fruit mixed with Harra (Terminalia Chebula) and Amla (Emblica officinalis) is useful in digestion. Fruits are soaked in water, and that water is used to cure cough. Fruit powder given orally with Sounth, Haldi and Rock salt in cough and cold.

Terminalia chebula Retz., Syn. Myrobalanus chebula (Retz.) Gaertn. (Harra) Combretaceae: Juice of stem bark given for stomach pain. The fruit decoction is used twice a day for 15 days in bleeding and ulceration of gums. Fruit juice used to reduce the body heat and to cure intestinal ulcers.

Tinospora cordifolia (Willd.) Miers. ex Hook. F. and Thomas (Amrita or Giloe) Menispermaceae: The juice of stem is taken orally as tonic. After long illness, the juice of the plant removes the weakness along with side effects of antibiotics. Dry stem constitutes drug, which is used as tonic in diarrhea and chronic dysentery. Extract of fresh root given orally with honey in fever. Paste of bark applied topically with castor oil in rheumatism.

Vernonia cinerea (Linn.) Less., Syn. Conyza cinera Linn. (Sahadevi) Asteraceae: Decoction of root is given in diarrhea and stomachache. Juice of leaves is given in insomnia fever, worms and cough. Seed paste is a good remedy for skin diseases and killing head lice. Leaves poultice used for eczema and ringworm.

Vitex negundo Linn., Syn. V. bicolor Willd. (Nirgundi) Verbenaceae: The extract of the leaves is used in body pain and in skin diseases. Decoction of leaves and roots given orally to children against diarrhea during teething. A pillow stuffed with the leaves is placed under the head for relief of headache.

\section{DISCUSSION AND CONCLUSION}

Based on the present study, it has been found that the tribal community of central India is rich in ethno-biological knowledge, which has been transmitted from one generation to another. The present study also revealed that the tribal communities living in the same region have their own traditional ethno-botanical knowledge. The methods used for curing diseases have been found to be different from one community to other. This is because of their socio-economic structure, ancient traditional knowledge and beliefs. Their livelihood is totally dependent on ecological surroundings and they use simple technology to sustain their life, which seems totally conservative. The present study emphasized that there is a profound and growing knowledge gap between old and younger generations. People of more than 50 years age know a lot about wild plant products as compared to younger generation (Pandey and Bisaria 1997).

Earlier the tribals of the region were harvesting medicinal plants at a particular time and date, and have belief that at this particular time it has more therapeutic value. It is evident from the modern science that at particular time the herb contains optimum active ingredients. These types of traditional harvesting practices will be helpful in providing quality raw material on sustainable basis and tool for conservation. The efforts are being made to document such non-destructive traditional harvesting practices for conservation as well as regulated and sustainable harvest. Considering conservation priorities, medicinal plant species yielding bark, root, gum, rhizome, flowers and whole plant as useful product in the manufacture of herbal drugs are more important. 
The medicinal plants provide numerous opportunities to the state to advance rural well being. Because medicinal plants are one of the few natural products that sell at premium prices. Thus, the global clamor for more herbal ingredients creates possibilities for the commercial cultivation of medicinal plants. Such endeavor could help raise rural employment in the developing countries, and perhaps contribute to the health of millions. The tribals of the region are still collecting gums, leaves, bark, flowers, and fruits of various medicinal plants to supplement their income.

\section{ACKNOWLEDGEMENT}

Authors are thankful to the Principal, Govt. Autonomous Maharaja College Chhatarpur and H.O.D. Botany Prof. Dr. L.C. Chaurasia for facilities and encouragement.

\section{REFERENCES}

Arjariya, A. and K. Chaurasia. 2008. Ethno botanical remedies of some gastrointestinal problems from Chhatarpur District (M.P.), Muzaffernagar. J. of Nature Conservation, 20(1):47-52.
Jain, S.K. and A.K. Goel. 1995. A Manual of Ethnobotany. (ed.) Jain, S.K. Scientific Publishers, Jodhpur, pp. 142-153.

Pandey, A.K. 2000. Strategies for effective conservation of medicinal plants. In: Integrated Management of Plant Resources. (eds.) Rai, M.K., A. Verma and R.C. Rajak. Scientific Publishers, Jodhpur (India), pp. 6874.

Pandey, A.K. and A.K. Bisaria. 1997. Rational utilization of important medicinal Plants: A tool for conservation. Indian Forester, 124(4):197-206.

Rai, M.K. and A.K. Pandey. 1997. Folk medicines of Gond tribe of Seoni district, M.P., India. $J$. Non-Timber Forest Products. 4(1/2):61-69.

Rai, M.K., A.K. Pandey and D. Acharya. 2000. Ethno-medicinal plants used by Gond tribe of Bhanadehi, district Chhindwara, Madhya Pradesh. J.Non-Timber Forest Products, 7(3/4):237-240. 